\title{
Robustness of a Thixoforming Production Line
}

\author{
J.-C. Pierret ${ }^{1, a}$, A. Rassili, ${ }^{1, b}$, G. Vaneetveld ${ }^{1, c}$, J. Lecomte-Beckers ${ }^{2, d}$ and \\ R. Bigot ${ }^{3, e}$ \\ ${ }^{1}$ ThixoUnit ULg, PIMW B56, University of Liège, Sart Tilman 4000 Liège - Belgium \\ ${ }^{2}$ MMS, University of Liège B52, Sart Tilman 4000 Liège - Belgium \\ ${ }^{3}$ LGIPM, ENSAM, 4 rue Augustin Fresnel, 57078 Metz Cedex 03 - France \\ ajc.pierret@ulg.ac.be, ba.rassili@ulg.ac.be, , cg.vaneetveld@ulg.ac.be, \\ jacqueline.lecomte@ulg.ac.be, ${ }^{\mathrm{e}}$ regis.bigot@metz.ensam.fr
}

Keywords: Thixoforging, steel, high melting point alloys, robustness, production line.

\begin{abstract}
The development of the thixoforming process made great progress since its beginning. But whereas thixoforming of aluminium and other low melting point alloys is now an industrial reality, thixoforming of high melting point alloys, as steel, is still at the research level. High temperature issues, die wearing and production rate are problems that must be solved and are more and more investigated. This work is a study of the robustness of a complete thixoforming unit dealing with steel. This flexible unit allows parts of various shapes be formed in conditions close to industrial ones. The study focus on the heating strategy, heat exchanges between the slug and the tool, the feeding and the cycle time. In this work, modelling has been used to simulate heating and feeding. In parallel, experiments have been made to obtain the needed parameters, to validate the modelling and to evaluate the capacities of such a line.
\end{abstract}

\section{Introduction}

During last years, thixoforming of aluminium and magnesium reached a development level sufficient to be accepted by the industry. Even if steel thixoforging didn't still attain its maturity, the possibility to transfer it in the industrial world in a mid-term future appears. So the capabilities of this technology have to be studied from an industrial point of view. With this idea, we developed a complete production line to produce steel thixoformed parts. In order to allow the technology transfer, appropriated modelling models also have to be developed and will be used to design the tools, to predict die-filling or to reduce the defects. One of the main features of a production line is its robustness, so that it is capable of producing good quality parts continuously, even if the forming cycles are not exactly the same. So the influence of the forming parameters has to be evaluated.

The first part of this paper introduces the experimental production line and its main features. The second section gives the experimental results obtained and their comments. These results are mainly load curves and simulation results. The last point deals with the capabilities of the line.

\section{Experimental device}

Overview. The overall production line is schematised on figure 1 . The mains components are the hydraulic press (1), the inductive heating (2) and the two robots $(3,4)$.

Hydraulic press (1). Maximum slide load is $500 \mathrm{kN}$, two punches have a maximum load of $100 \mathrm{kN}$ each. Slide is used to keep a blocking force on the tool and the part is formed by the punches. The maximum speed of these punches is about $0,75 \mathrm{~m} / \mathrm{s}$.

Inductive heating (2). Maximum power is $150 \mathrm{~kW}$. Frequency could vary from 2 to $10 \mathrm{kHz}$.

Robot1 (3). This robot is used for the feeding. It puts the part in the inductive furnace and moves it to the press when heating is done. The gripper is closed and argon is injected to prevent scaling. Transfer from the inductor to the press is done in approximately 3 seconds. 
Robot2 (4). This robot removes the parts from the press and puts them into a box. It also cleans and lubricates the dies. The lubricant is boron nitride suspension.

Tool (5). During this research we used the dies presented in [1] which are used to make a part of car engine. This one is a demonstration part redesigned for the thixoforming and classically made by drop forging of steel.

Raw material. For this study we used C38L2T steel, which is a modification of the C38 steel. Thanks to this modification, the solidus is lower and the semi-solid window is larger [2]. Billets are cut from extruded bars.

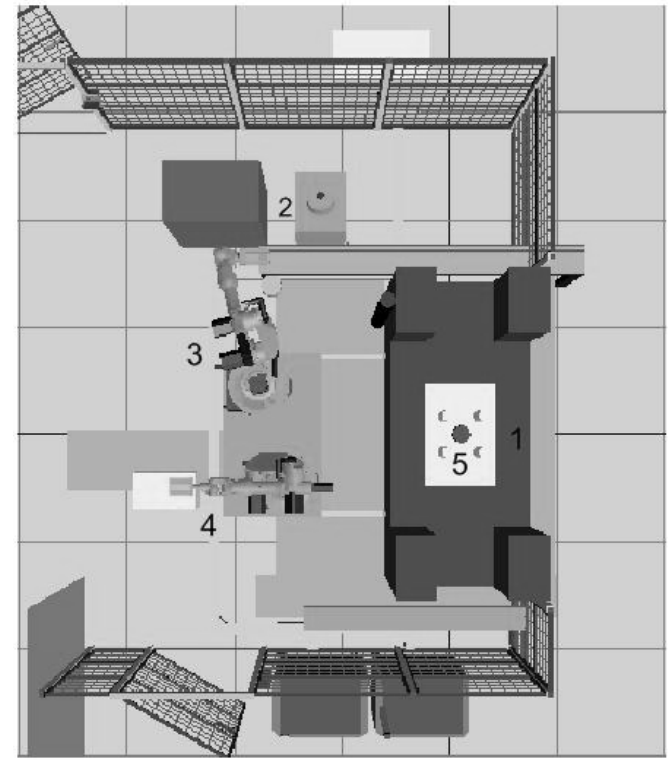

Fig.1 The production line

\section{Results and discussion}

It is established that heating is a step of major importance in the semi-solid processing [3]. Indeed, the temperature of the slug leads its liquid fraction and we know that this is the main parameter of the process. Moreover, the temperature distribution inside the billet also has an impact on the slurry behaviour and on the occurrence of defects. In this work we studied the influence of the billet's temperature and of the heating rate.

Influence of the billet's temperature. In our equipment, we have to program a heating cycle and this cycle is applied to the inductor. However, as the surrounding conditions are not always the same, the final temperature of the billet is also not exactly the same. This effect is quite important as our inductors are generally sealed in concrete and this concrete is also heated by the billets. In our experiments, if we heat the parts one after the other, the final temperature of the fifth one is around $70^{\circ} \mathrm{C}$ higher than the first one. After these five firsts parts, we didn't notice any further increase. This issue could be solved by using a pyrometer to stop the heating when the desired temperature is reached but this is not possible with our setting.

Influence of the heating time. Different studies $[4,5,6]$ have shown that the heating rate and the holding time have an impact on the liquid fraction and on the microstructure of the slug. Figure 2 shows the temperature records at the centre of the billet for two different heating strategies. The first one is really quick and is done in only 45 seconds, the second one takes more than two minutes. For the first strategy, the aim was to reach the desired temperature as fast as possible, so three high power steps were used. For the second strategy, the aim was to obtain a homogenous temperature, so 7 steps of decreasing power were used as well as long homogenisation steps.

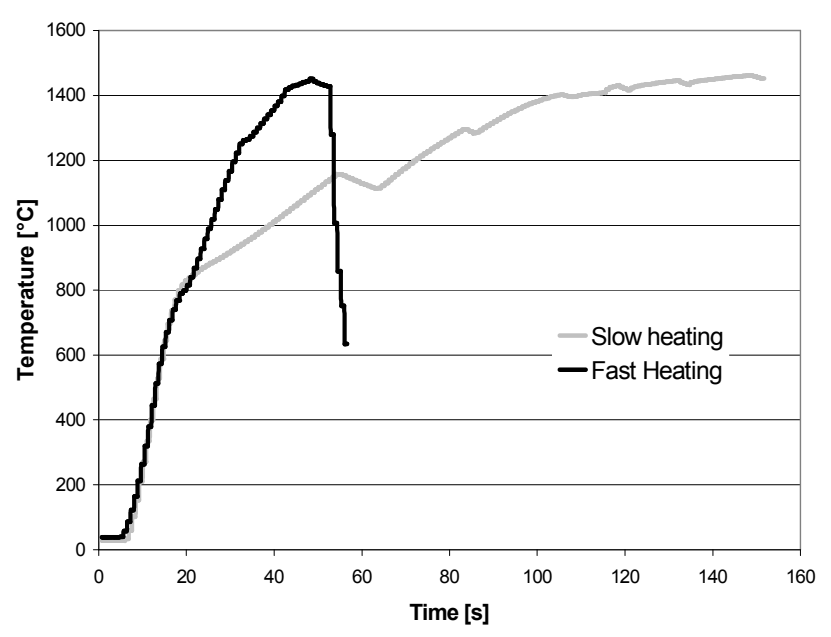

Fig.2 Heating strategies 
The temperature range, between the centre of the billet and a point at mid-height and at $3 \mathrm{~mm}$ of the surface, three seconds (transfer to the press time) after the end of heating, is about $15^{\circ} \mathrm{C}$ for the fast heating and $8^{\circ} \mathrm{C}$ for the slow one.

The forming loads measured during the forming of the part for the two heating strategies are presented on figure 3 . As we could see, the required load is about $30 \%$ lower when using the slow heating cycle. Two effects could explain this high difference. First one is that the liquid fraction is not the same due to the different heating rates. In fact, Püttgen [4] has shown that a higher heating rate leads to a lower liquid fraction due to the higher temperature differences inside the slug. This higher liquid fraction

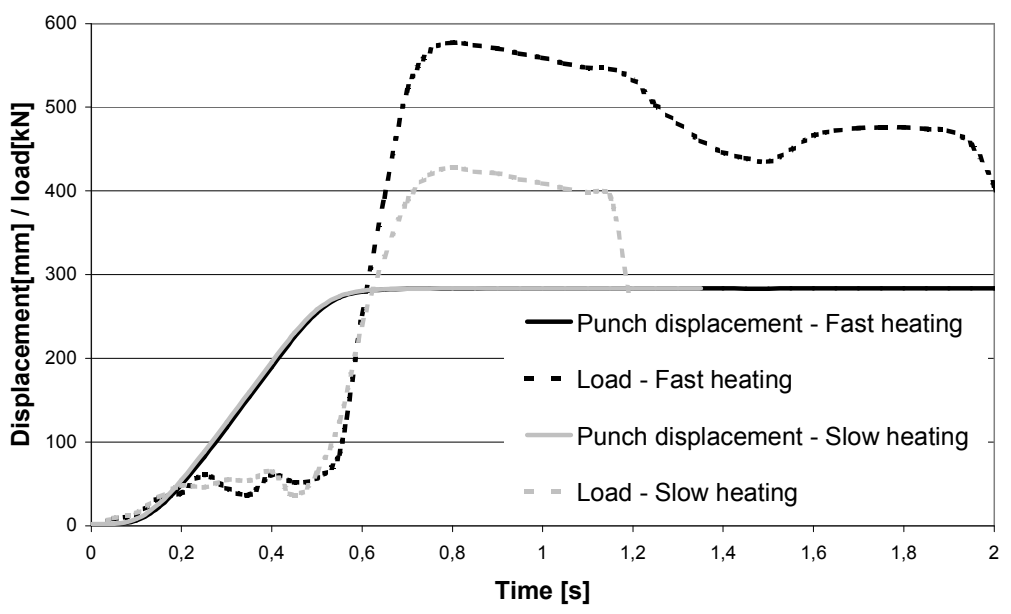

Fig.3 Forming loads in function of heating rate tends to decrease the forming load for slow heating but could also be the origin of defects as porosities or hot tearing. The second effect that could explain the difference of the forces is the holding time. When using the slow heating, the material is kept in the semi-solid state for approximately 40 seconds, but this time is reduced to 10 seconds if we use the fast heating. Omar [5] and Seidl [6] have shown that holding the material at the same temperature in the semi-solid state for some time have an impact on its microstructure, mainly on the size and shape of the grains. The longer the holding time, the more spherical are the grains.

Influence of the transportation. As already mentioned, transportation of the billet from the inductive furnace to the press is done by a robot in about three seconds. This time has to be as short as possible because during transportation, the billet is cooled and scaling could occur. To avoid scaling, we inject argon as a protective gas but this could also cool the billet and solidify its surface. In order to observe the influence of the transportation time, we changed the robot's speed and made parts. Figure 4 compares the forming loads (displacements being the same) used to produce a part after a transportation time of three or five seconds. As we could see, increasing the transfer time of two seconds increases the forming load of around $10 \%$. This is quite easy to explain as the slug is cooled during the transfer, its main liquid fraction decreases and this leads to a higher consistency of the material. During the short time of transfer, only this cooling effect is effective, the modification of the microstructure which could lead to an improvement of the grain's shape is too slow, so the two more seconds are detrimental. Figure 5 shows the temperature distribution inside the billet at the end of heating and three and five seconds after. One can see that the temperature range decreases as the conduction inside the billet is faster than convection to the outside. This distribution was calculated on the FEM software GetDP [7]. The

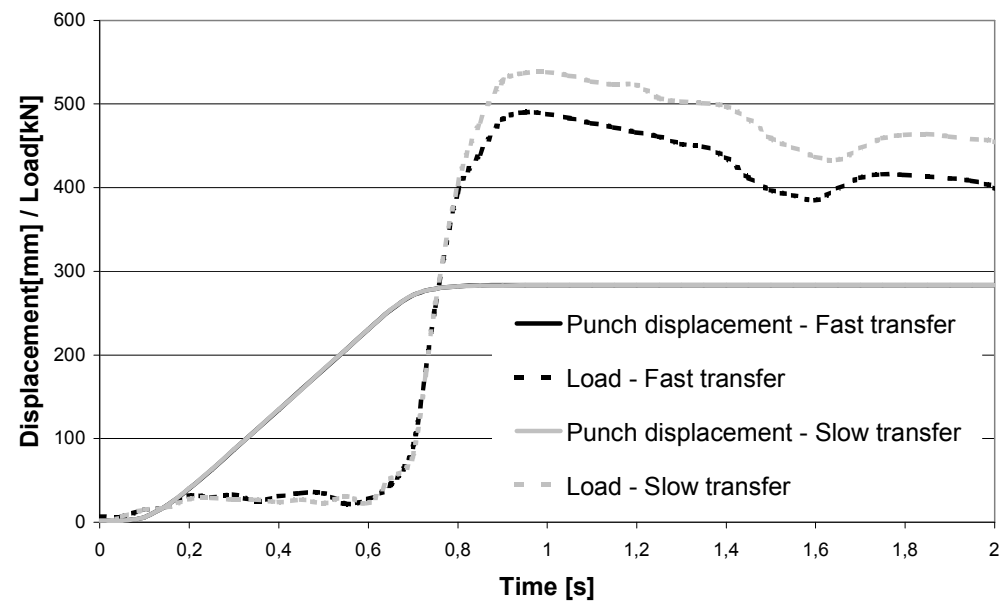

Fig.4 Influence of the transfer time 
temperature range decreases from $[1435-1455]^{\circ} \mathrm{C}$ to $[1430-1436]^{\circ} \mathrm{C}$ and $[1420-1423]^{\circ} \mathrm{C}$ respectively. If we compare these temperatures to the liquid fraction vs. temperature curve we could estimate that the main liquid fraction is reduced from $25 \%$ to $15 \%$ or $10 \%$. This reduction of the liquid fraction give not only a growth of the consistency but moreover, the solidified material has a dendritic structure which is not desired in thixoforming.

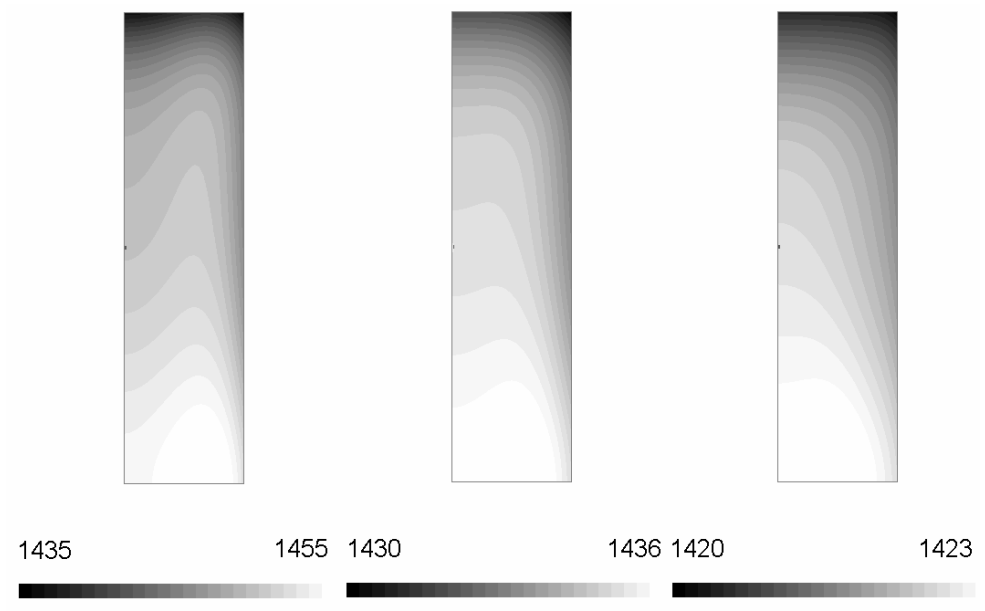

Fig.5 Temperature distribution at the end of heating (a) and after 3 (b) and 5 (c) seconds

Influence of the forming speed. Figure 6 presents the forming loads recorded for two different punch speeds. The displacement are respectively 400 and $300 \mathrm{~mm} / \mathrm{second}$ and the force increases of about $15 \%$. There are still two effects which explain this difference. The first one is the shear thinning effect [8], indeed, the shear rate increases with the forming one and the consistency is supposed to decrease when the shear rate rises. The second explanation is a thermal one [9]. As the forming speed is lower, the forming time is higher and so the part's cooling during the forming is also higher. In this case, the forming time is about 0,25 seconds higher with the low speed than with the high speed. But the difference of load is approximately

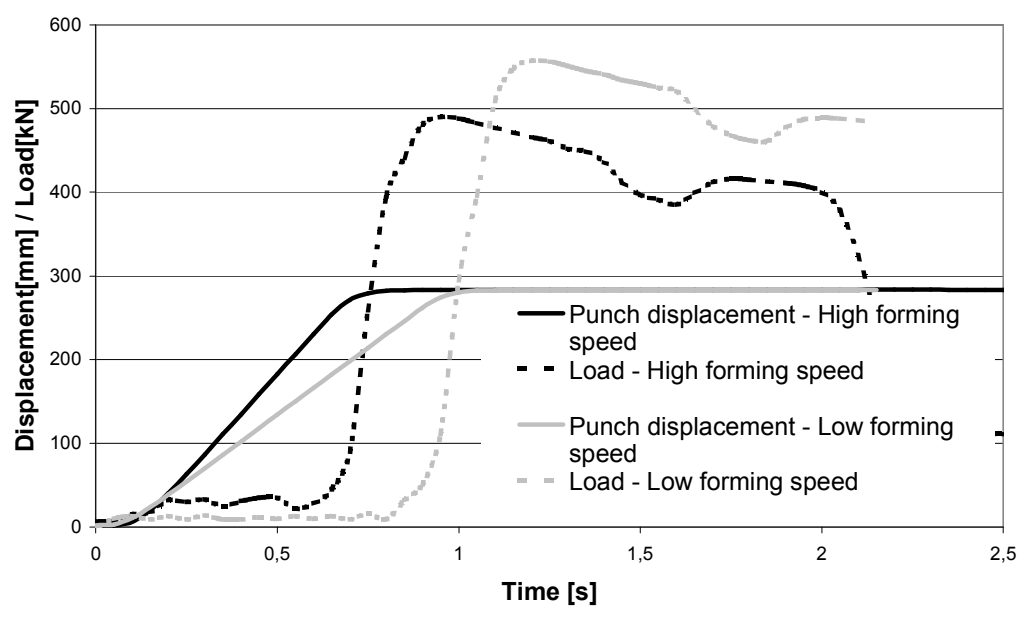

Fig.6 Impact of the forming speed the same than the one observes when we increase the transfer time of 2 seconds, so the thermal effect alone can not explain the difference of the forces and the shear thinning effect must be taken into account.

Productivity. With the fast heating strategy and the fast transfer, the production cycle's time is approximately one minute. So the line could produce about 60 parts per hour. This production falls to 25 parts per hour with the slow heating. This production rate could be highly increased by the use of two inductors in parallel because the heating step take at least $80 \%$ of the production time. It appears that a rate of 100 parts per hour is clearly realistic in this view, such productivity is close to the industrial requirements. 


\section{Conclusion}

The aim of this work is to analyse the robustness of a thixoforming production line. So the interest is to evaluate if the deviation of the parameters value which appears during production will have an impact on the part's quality.

In our configuration, the parameter that could vary during the heating is the final main temperature inside the billet. Particularly, we have seen that the accumulation of heat in the concrete could rise the temperature up to $70^{\circ} \mathrm{C}$ higher than expected. However, this issue is only effective for the five firsts parts, for the followings ones the system reaches a steady-state. Moreover, decreasing the thickness of the concrete tends to minimize this effect.

The transport time was also shown to be important as the slug's temperature and so the liquid fraction decrease quickly. We have seen that a few more seconds could lead to a great increase of the forming force due to the growth of the solid fraction and the solidification of a part of the liquid in a dendritic structure.

Finally, the forming speed is a very important parameter. As for the transport time, the cooling that occurs at low forming rate could bring the material to a lower liquid fraction and so a higher consistency but moreover, a low punch speed means a low shear rate and this still increases the viscosity.

This study shows that production of steel thixoforged parts is possible, but there are still some work to do on the die's lifetime, on modelling and on parameters identification before transferring the technology to the industrial world. Nevertheless, this transfer appears more and more as a question of time.

\section{Acknowledgments}

The authors gratefully acknowledge the University of Liège, the First Europe Project and the Walloon Region for their financial support.

\section{References}

[1] D. Fischer, B.A. Behrens, B. Haller, A Rassili, J.C. Pierret, H. Klemm, A. Studinski, B. Walkin, M. Karlsson, M. Robelet, L. Natale and F. Alpini : Series production of thixoformed steel parts, Trans. Tech Publications, Solid State Phenomena Vols. 116-117, Switzerland, (2006).

[2] M. Robelet, A. Rassili and D. Fischer : Steel grades adapted to the thixoforging process: metallurgical structures and mechanical properties, Trans. Tech Publications, Solid State Phenomena Vols. 116-117, Switzerland, (2006).

[3] M. C. Flemings: Metall. Trans. A, (1991), 22A, 957-981.

[4] W. Püttgen and W. Bleck : DTA-Measurements to Determine the Thixoformability of Steels, Steel Research Int. 75 (2004) No. 8/9

[5] M.Z. Omar, E.J. Palmiere, A.A. Howe, H.V. Atkinson and P. Kapranos : Thixoforming of a high performance HP9/4/30 steel, Materials Science and Engineering A 395 (2005) 53-61

[6] I. Seidl and R. Kopp : Semi-Solid Rheoforging of Steel, steel research int. 75 (2004) No. 8/9

[7] A. Rassili, C. Geuzaine, W. Legros, M. Bobadilla, A. Cucatto, M. Robelet, S. Abdelfattah, J. Dohmann, Ch. Hornardt : Simulation of adequate inductive heating parameters and the magneto-thermal coupling involved in the SSM processing of steels, $6^{\text {th }}$ International Conference Semi-Solid Processing of Alloys and Composites, Turin (2000). 
[8] P.A. Joly, R. Mehrabian : The rheology of a partially solid alloy, Journal of Materials Sciences 11, (1976), 1393-1418

[9] P. Cezard, R. Bigot, V. Favier, M. Robelet : Thixoforming of steel - Influence of thermal parameters, Solid State Phenomena, vol. 116-117 (2006), 721-724 
Semi-Solid Processing of Alloys and Composites X doi:10.4028/www.scientific.net/SSP.141-143

Robustness of a Thixoforming Production Line doi:10.4028/www.scientific.net/SSP.141-143.207 